\title{
Isolation and detailed characterisation of the first sterigmatocystin hyperproducer mould strain in Hungary
}

\author{
Cs. Dobolyi ${ }^{1}$, K. Inotai ${ }^{2}$, I. Bata-Vidács ${ }^{2,3 *}$ @, D. Sárkány ${ }^{2}$, O. Csernus ${ }^{4}$, \\ S. Kocsubé ${ }^{5}$, B. Tóth ${ }^{6}$, A. Szekeres ${ }^{5}$ and J. Kukolya ${ }^{2,3}$
}

${ }^{1}$ Department of Environmental Safety and Ecotoxicology, Szent István University, Páter K. út 1, H-2100 Gödöllö, Hungary

${ }^{2}$ Department of Environmental and Applied Microbiology, National Agricultural Research and Innovation Centre, Herman Ottó u. 15, H-1022, Budapest, Hungary

${ }^{3}$ Research Group for Food Biotechnology, Buda Campus, Hungarian University of Agriculture and Life Sciences, Herman Ottó u. 15, H-1022, Budapest, Hungary

${ }^{4}$ Department of Brewing and Distilling, Faculty of Food Science, Szent István University, Ménesi út 45, H-1118, Budapest, Hungary

${ }^{5}$ Department of Microbiology, Faculty of Science and Informatics, University of Szeged, Közép fasor 52, H-6726 Szeged, Hungary

${ }^{6}$ Hungarian Academy of Sciences, Martonvásár, Hungary

\section{ORIGINAL RESEARCH PAPER}

Received: December 14, 2020 • Accepted: January 19, 2021

Published online: February 20, 2021

(C) 2021 The Author(s)

\section{ABSTRACT}

Aspergillus strains were isolated from Hungarian mills in order to get information on the appearance of sterigmatocystin (ST) producing moulds, whose presence has never been demonstrated in Hungary. Fungal isolates were classified into nine morphotypes, sections Nigri, Nidulantes, Versicolores (two morphotypes), Circumdati, Flavi (two morphotypes), Clavati and Terrei by classical mycological assays. ST producing strains could be classified into section Versicolores. ST production of the isolates was assessed by liquid and solid phase growth experiments and compared to ST producing reference strains: Aspergillus pepii

*Corresponding author. Tel.: +36 70 3373059, E-mail: batane.vidacs.ildiko@uni-mate.hu 
SzMC 22332, Aspergillus versicolor SzMC 22333, Aspergillus griseoaurantiacus SzMC 22334 and Aspergillus nidulans RDIT9.32. Four of our isolates marked as $\mathrm{Km} 11, \mathrm{Km} 14, \mathrm{Km} 26$ and $\mathrm{Km} 31$ showed ST production in liquid medium. ST production on solid phase corn grit substrate was measured after three weeks of incubation, and $\mathrm{Km} 26$ isolate proved to be the most prominent with a toxin concentration of $277.1 \mu \mathrm{g} \mathrm{g}^{-1}$, surpassing all reference strains. The toxin-producing ability of $\mathrm{Km} 26$ isolate was also tested in a field experiment, where corn was infected. By the end of the experiment, ST level of $19.56 \mu \mathrm{g} \mathrm{kg}^{-1}$ was measured in infected corn.

Molecular taxonomic identification of the $\mathrm{Km} 26$ strain was performed using internal transcribed spacer (ITS), calmodulin and tubulin sequence analyses. Based on these studies, strain $\mathrm{Km} 26$ was identified as Aspergillus creber.

Here we report that an ST-producing A. creber strain has appeared in Hungary, and the Km26 strain is the first known extreme ST-producing mould in this country. As a result of climate change, aflatoxin B1 producing Aspergillus flavus strains have appeared in Hungary in the last decade. As strain Km26 is the only A. creber isolate in Hungary so far, there is no sign of mass prevalence, and due to the lower temperature optimum of the species compared to A. flavus, its appearance is probably not related to climate change.

\section{KEYWORDS}

sterigmatocystin, Aspergillus creber, flour-mill, molecular taxonomy, mycotoxin production, field test, morphotype, sterigmatocystin analytics

\section{INTRODUCTION}

Fungi are the major cause of spoilage in stored grain. The Food and Agriculture Association estimates that $25 \%$ of the world's food crops are affected by mycotoxins during growth and storage. The damage of fungi is second only to that caused by insects in stored grain products. Many of the fungi cause damage to the crops themselves with little or no toxic effects on humans and animals (Scott, 1994). Mould growth can occur either before harvest or after harvest, during storage, on/in the food itself often under warm, damp, and humid conditions (Neme and Mohammed, 2017; WHO, 2018). Scientists estimate that there are 300-400 mycotoxins presently identified with more being isolated as new techniques and processes evolve. The most frequently found mycotoxins are aflatoxin, deoxynivalenol, zearalenone, fumonisin and T-2 as far as grain crops are concerned (USDA, 2006).

Sterigmatocystin (ST) serves as precursor of aflatoxins biosynthesis pathways and is also toxic, mutagenic and carcinogenic (Berry, 1988). The biological activity of ST is much like but less toxic than aflatoxin B1 (Bennet and Klich, 2003). The $\mathrm{LD}_{50}$ value of ST for male rats is $60-800 \mathrm{mg} \mathrm{kg}^{-1}$, whereas that of aflatoxin B1 is $5.5 \mathrm{mg} \mathrm{kg}^{-1}$. The International Agency for Research on Cancer (1987) classified ST as a group 2B carcinogen, which means it is possibly carcinogenic to humans. ST is produced by several species of Aspergillus.

According to recent studies, subgenus Nidulantes consists of nine sections including species formerly classified to section Versicolores (Chen et al., 2016). This group was revised several times (Gams et al., 1985; Kozakiewicz, 1989; Peterson, 2008; Jurjevic et al., 2012), and recent phylogenetic studies have shown that members of this clad cannot be considered as a separate section, therefore, species belonging to this group have been merged with section Nidulantes to maintain the monophyly of the latter (Hubka et al., 2016; Chen et al., 2016). The most relevant member of this group is Aspergillus versicolor, proven to be responsible for serious health 
hazards including human and animal mycoses by contaminating food and feed with ST and playing role in Sick Building Syndrome (SBS). Currently 17 species are accepted in the $A$. versicolor clad i.e. Aspergillus amoenus, Aspergillus austroafricanus, Aspergillus creber, Aspergillus cvjetkovicii, Aspergillus fructus, Aspergillus griseoaurantiacus, Aspergillus jensenii, Aspergillus protuberus, Aspergillus puulaauensis, Aspergillus subversicolor, Aspergillus sydowii, Aspergillus tabacinus, Aspergillus tennesseensis, Aspergillus venenatus and A. versicolor (Jurjevic et al., 2012), as well as two recently described species Aspergillus hongkongensis (Tsang et al., 2016) and Aspergillus pepii (Jakšić Despot et al., 2017). All species belonging to this group are able to produce ST but A. austroafricanus, A. tabacinus and A. hongkongensis.

It has been noted that $A$. versicolor is the major ST producer (Tabata, 2011). Zhao et al. (2018) determined the occurrence of ST in 178 food samples (32 wheat samples and 146 wheat products) purchased from Chinese supermarkets. They have found that $53.1 \%$ of wheat, $59.2 \%$ of crackers, $20.8 \%$ of white bread and $16 \%$ of whole meal bread samples were contaminated with ST, the mean levels were $0.07,0.79,0.12$ and $0.12 \mu \mathrm{g} \mathrm{kg}^{-1}$, respectively. In total 277 cereal samples, comprising 93 samples of unprocessed cereal grains and 184 cereal products were collected and analysed in the UK by Leon et al. (2015). ST was found in $4 \%$ of the investigated cereal samples at $>0.5 \mu \mathrm{g} \mathrm{kg}^{-1}$ concentration, in line with the results of the wider EFSA survey of 1,142 cereal samples (Mol et al., 2016). Another $12 \%$ of the cereal samples had ST content in the range of $0.1-0.5 \mu \mathrm{g} \mathrm{kg}^{-1}$. ST was present in UK samples at levels above $0.1 \mu \mathrm{g} \mathrm{kg}^{-1}$ in $14 \%$ of unprocessed grains and $17 \%$ of cereal products (Leon et al., 2015). Although the levels are low, this demonstrates the need for more comprehensive surveys for this mycotoxin in wheat and cereal products.

The mycobiota of flour-mills is regarded a prominent site to search for mycotoxin producing fungi for subsequent toxin-production investigations. Fungal species have been isolated and identified from Argentinian flour-mills by Aringoli et al. (2012). Cladosporium and Alternaria were abundant at every phase of milling, Aspergillus predominated in the wheat conditioning zone, and presence of Penicillium and Eurotium decreased with processing steps. They also found that wheat was more contaminated than grits and flour, and species belonging to Aspergillus, Eurotium and Mucoraceae families were the most abundant. The potential toxigenic capacity of the Aspergillus flavus isolates was also studied. Though aflatoxin concentrations showed acceptable levels when studied in vitro, 53\% of the A. flavus isolates produced aflatoxins. The mycobiota of flours was studied by Weidenbörner et al. (2000), who found dominance of Aspergillus spp. accounting for approximately $80 \%$ of the isolates. Fungi of the genus Penicillium spp. were present at less extent: $8 \%$ of the isolates of whole wheat flour and $15 \%$ of white wheat flour belonged to this genus. Aspergillus candidus was the mould most frequently encountered. Penicillium aurantiogriseum, Cladosporium cladosporioides, A. flavus, Eurotium herbariorum, Penicillium griseofulvum, Penicillium brevicompactum and Penicillium viridicatum were less abundant. From the 3,563 identified fungi 93.3\% (32 species) belonged to the group of toxigenic moulds. Demirci et al. (2003) also stated that representatives of Aspergillus, Penicillium, Fusarium and Alternaria genera are more responsible for producing mycotoxins.

The aim of our study was to isolate and characterise possible ST producing Aspergillus strains from Hungarian flour-mills, and to determine their ST producing capabilities by in vitro and in vivo experiments. 
Table 1. Sampling sites of sample collection from two flour-mills in Central Hungary in 2017

\begin{tabular}{lcc}
\hline & Flour-mill A & Flour-mill B \\
\hline Wheat grain & + & + \\
Mixed milled & + & + \\
After sieving & + & - \\
Flour 1 & + & - \\
Flour 2 & + & - \\
Aerial sediment from the floor & + & + \\
\hline
\end{tabular}

+ : where samples were collected; - : where samples were not collected.

\section{MATERIALS AND METHODS}

\subsection{Isolation process of fungal contaminants}

In order to study the Aspergillus propagula in flour-mills, 11 and 12 samples (flours, pulverised indoor mixtures and aerial sediments) were collected from different sampling sites (Table 1) of two Central Hungarian flour-mills, respectively. The sample collection year was 2017. Ten grams of the samples were mixed with $90 \mathrm{~mL}$ sterile distilled water and subjected to ultrasonic treatment for $5 \mathrm{~min}$ to obtain finely homogenised suspension. Then $100 \mu \mathrm{L}$ from the $5^{\circ} 10$-fold serial dilutions were spread on Rose Bengal Chloramphenicol Agar (Scharlau, Barcelona, Spain) plates supplemented with $100 \mathrm{mg} \mathrm{L}^{-1}$ streptomycin. The plates were incubated at room temperature for 7 days. Strains were selected from the plates for further studies on the base of morphological features.

\subsection{Morphological studies}

Colony morphology studies were carried out on fungi grown on PDA (Potato Dextrose Agar, VWR), DRCB (Dichloran Rose-Bengal Chloramphenicol Agar, Scharlau), and Czapek-Yeast Extract Agar (Scharlau) plates. Microscopic studies were done with light microscopy (KERN OBN 147 fluorescent microscope) at $400 \times$ magnification.

\subsection{Measurement of ST production in liquid medium (A), in corn grit (B) and in field studies (C)}

A - Based on the morphological studies four assumed Versicolores flour-mill isolates (Km11, $\mathrm{Km} 14, \mathrm{Km} 26$ and Km31) and four A. versicolor strains (SzMC 22332, SzMC 22333, SzMC 22334, SzMC 22335) (from the Fungal Strain Collection of Szeged, Hungary) were selected for ST production studies. Aspergillus nidulans served as ST producing control strain (Németh et al., 2016). The cells were grown in YES broth $(2 \%(\mathrm{w} / \mathrm{v})$ yeast extract, $15 \%(\mathrm{w} / \mathrm{v})$ saccharose) at room temperature in dark, for 6 days. ST production was detected with thin layer chromatography (TLC).

B - To determine the ST production of Aspergillus strains, samples of $10 \mathrm{~g}$ corn grit with $8 \mathrm{~mL}$ distilled water were sterilised by autoclaving. To provide mould inoculum for the studies, strains of experiment A were inoculated onto PDA (Potato Dextrose Agar, VWR) plates, and after 7 days of incubation at room temperature, in the dark, mould suspensions were prepared in 
sterile water with the help of Potter homogeniser with final concentrations of $10^{7}$ conidiospore $\mathrm{mL}^{-1}$. The corn grit units were inoculated with $200 \mu \mathrm{L}$ mould suspension and incubated at $25{ }^{\circ} \mathrm{C}$ for 3 weeks. Quantitative determination of the produced ST was done by High Performance Liquid Chromatography (HPLC) technique.

C - Field trials were carried out at the Experimental Station of the Cereal Research NP Company, Kiszombor, Hungary. The soil type was alluvial with high clay content, previous crop was wheat. The sowing time of maize hybrid Szegedi 521 was on the 28th of April 2018. The experiment consisted of six, $10 \mathrm{~m}$ long plots, row space of $75 \mathrm{~cm}$ and plant distance of $20 \mathrm{~cm}$. One plot served as control, and five plots were inoculated by our best ST producing isolate, Km26. For mid-ear inoculation the toothpick method described in detail by Szabó et al. (2018) was used. On the 7th of July, 6 days after midsilking, a Km26 strain infected toothpick was inserted in the middle of each upper ear and kept there until harvest. For toxin analyses five average infected ears/plot were sampled.

\subsection{Thin Layer Chromatography method}

Twenty millilitres of fully grown cultures of the investigated fungi in YES broth were mixed with $10 \mathrm{~mL}$ dichloromethane, and extracted with vigorous shaking and leaving to stand for $20 \mathrm{~min}$ in the dark. Swimming fungal flocks were squeezed with a glass rod to extract intermycelial toxin. The bottom solvent phase was pipetted to a clear $15 \mathrm{~mL}$ Falcon tube, then centrifuged at 3,000 rpm for $10 \mathrm{~min}$. After centrifugation, $2 \mathrm{~mL}$ extract was transferred to an Eppendorf tube and the dichloromethane was evaporated at $40{ }^{\circ} \mathrm{C}$ in a thermo shaker (BIOSAN TS-100) under a fume dome. The dried material was dissolved in $100 \mu \mathrm{L}$ dichloromethane. Ten microlitres of sample was slowly pipetted onto the starting point of a silica gel (TLC Silica Gel 60, 25 Aluminium Sheets $20 \times 20$, Merck). The running buffer was toluene:ethyl acetate:formic acid in ratio 6:3:1. Five $\mu \mathrm{L}$ of $1 \mu \mathrm{g} \mathrm{mL}^{-1}$ ST standard (Merck KGaA, Darmstadt, Germany) was used as control. The silica gel was placed into a developing tank vertically, and left under a fume hood until the solvent front reached the required distance. The gel was taken out and dried under the fume hood. The ST spots were visualised by long-wavelength UV light $(365 \mathrm{~nm})$.

\subsection{Quantification of ST by HPLC}

2.5.1. Sample preparation. From YES broth cultures $2 \mathrm{~mL}$ samples were taken, centrifuged at $13,000 \mathrm{rpm}$ for $10 \mathrm{~min}$, then the supernatant was extracted with $2 \mathrm{~mL}$ dichloromethane. The extracts were stored at $-20{ }^{\circ} \mathrm{C}$ until analysis.

To each culture flasks containing corn grit samples $20 \mathrm{~mL}$ methanol was added and the mixtures were transferred into a Stomacher bag. The samples were homogenised for $45 \mathrm{~s}$ in a Pulsifier instrument (Microgen Bioproducts Ltd., Camberley, United Kingdom) and left to stand in the dark for $24 \mathrm{~h}$, and then homogenised again for $45 \mathrm{~s}$ for thorough extraction. The supernatant of each sample was transferred to a $50 \mathrm{~mL}$ Falcon tube and centrifuged at $20{ }^{\circ} \mathrm{C}$, 3,000 rpm, for $10 \mathrm{~min}$. The supernatants were stored at $-20{ }^{\circ} \mathrm{C}$ until analysis.

Five g corn samples originating from field studies were extracted with $25 \mathrm{~mL} \mathrm{MeOH}$ as follows: first the samples were stirred vigorously for $2.5 \mathrm{~h}$ and then centrifuged at 3,000 rpm, for $15 \mathrm{~min}$, and $8 \mathrm{~mL}$ of the supernatant was evaporated. Evaporated samples were re-dissolved in $1 \mathrm{~mL} \mathrm{HPLC}$ grade $\mathrm{MeOH}$ and pipetted into an HPLC vial. 
2.5.2. LC-MS measurement. The ST content of the samples was determined by LC-MS. The system consisted of an LC-20ADXR pump, a DGU-20A5R degasser, a SIL-20AXR automatic sample dispenser, a CTO-10ASVP column thermostat, and a TSQ Quantum Access (Thermo) mass spectrometer.

Separation of ST was performed on a Gemini NX C18 $50 \times 2 \mathrm{~mm} 3 \mu \mathrm{m}$ (Phenomenex, Torrance, California, United States) column to which a Gemini NX C18 pre-column was connected. The mobile phase was built from $\mathrm{H}_{2} \mathrm{O}+0.1 \mathrm{mM}$ ammonium formate (eluent $\mathrm{A}$ ) and $\mathrm{MeOH}+0.1 \mathrm{mM}$ ammonium formate (eluent $\mathrm{B}$ ). The injection volume was $3 \mu \mathrm{L}$. The flow rate and the column temperature were $0.3 \mathrm{~mL} \mathrm{~min}^{-1}$ and $40{ }^{\circ} \mathrm{C}$, respectively. The $\mathrm{m} / z 310.02$ ion was chosen for the identification and quantification of ST, while the $m / z 281.05$ ion was chosen as the confirming ion. The retention time of ST was $6.57 \mathrm{~min}$.

The lower limits of quantification (LOQ) and detection (LOD) were established, with values of $5.45 \mathrm{ng} \mathrm{g}^{-1}$ and $1.36 \mathrm{ng} \mathrm{g}^{-1}$, respectively.

\subsection{Taxonomic identification of selected ST-producing strains}

Strains used for the molecular studies were grown in PDA for 2 days and the DNA was extracted from the mycelia using the Masterpure ${ }^{\mathrm{TM}}$ yeast DNA Purification Kit (Epicentre Biotechnologies) according to the supplier's instructions.

The taxonomic identification of the three most intense toxin producing strains based on the HPLC results were done at the Westerdijk Fungal Biodiversity Institute (Utrecht, the Netherlands). Upon arrival, the strains were grown on Malt Extract Agar (MEA) and Dichloran 18\% Glycerol Agar. DNA was extracted from one MEA plate after an incubation period of 3-4 days in the dark at $25^{\circ} \mathrm{C}$ using the Qiagen DNeasy Ultraclean ${ }^{\mathrm{TM}}$ Microbial DNA Isolation Kit. For all strains, fragments containing the Internal Transcribed Spacer 1 and 2 regions including the 5.8S gene (ITS), fragments containing a partial beta-tubulin gene (BenA), and fragments containing a part of the calmodulin gene $(C a M)$ were amplified. The used primers for identification were: ITS: LS266 (GCATTCCCAAACAACTCGACTC) and V9G (TTACGTCCCTGCCCTTTGTA); BenA: Bt2a (GGTAACCAAATCGGTGCTGCTTTC) and BT2b (GGTAACCAAATCGGTGCTGCTTTC); and CaM: CMD5 (CCGAGTACAAGGARGCCTTC) and CMD6 (CCGATRGAGGTCATRACGTGG).

The PCR fragments were sequenced with the ABI Prism ${ }^{\circledR}$ Big DyeTM Terminator v. 3.0 Ready Reaction Cycle sequencing Kit and analysed on an ABI PRISM 3700 Genetic Analyzer. Contigs were assembled using the SeqMan software of the LaserGene package. Obtained sequences were subjected to blast analysis using the BLAST engine of GenBank (https://blast.ncbi.nlm.nih.gov/ Blast.cgi) and the in house sequence database of the Westerdijk Fungal Biodiversity Institute.

\subsection{Statistical evaluation}

All measurements were carried out in three parallels. Means and standard deviations were calculated using the Excel 2007 software programme (Microsoft, CA, USA).

\section{RESULTS AND DISCUSSION}

\subsection{Morphological characterisation of moulds isolated from flour-mills}

According to colony morphological characteristics on PDA, DRCB and Czapek-yeast extract agar plates, Aspergillus candidate strains were selected. Further typing was carried out with the 
Table 2. Morphotypes of the isolates belonging to sections of the genus Aspergillus from flour-mills

\begin{tabular}{lccc}
\hline & & \multicolumn{2}{c}{ Source of isolates } \\
\cline { 3 - 4 } Morphotype & Aspergillus section & Flour-mill A & Flour-mill B \\
\hline Mt1 & Nigri & Km03, Km07 & Km18, Km20, Km22 \\
Mt2 & & $\mathrm{Km} 21$ \\
Mt3 & Versicolores & Km11, Km26 & $\mathrm{Km} 31$ \\
Mt4 & Versicolores & $\mathrm{Km} 01$ & $\mathrm{Km} 14$ \\
Mt5 & Circumdati & $\mathrm{Km} 25$ & \\
Mt6 & Flavi & & $\mathrm{Km} 17$ \\
Mt7 & Flavi & & $\mathrm{Km} 29$ \\
Mt8 & Clavati & $\mathrm{Km} 03, \mathrm{Km} 07$ & $\mathrm{Km} 18, \mathrm{Km} 20, \mathrm{Km} 22$ \\
Mt1 & Nigri & &
\end{tabular}

help of light microscopy. The detailed description of morphotypes 1-9 is provided in Supplement (S1) and the isolates' classification is presented in Table 2.

\subsection{Sterigmatocystin production of isolated strains}

3.2.1. ST detection in liquid medium. To select the best ST producing strain, A. versicolor SzMC 22332, SzMC 22333, SzMC 22334 and SzMC 22335; flour-mill isolates Km11, Km14, $\mathrm{Km} 26$ and $\mathrm{Km} 31$; and A. nidulans (as ST producing control) were grown for 6 days in YES broth at room temperature in the dark. ST production was detected by TLC in this experiment. Three of the eight strains - SzMC 22332, SzMC 22334 and isolate Km26 - showed visible signals (Fig. 1).

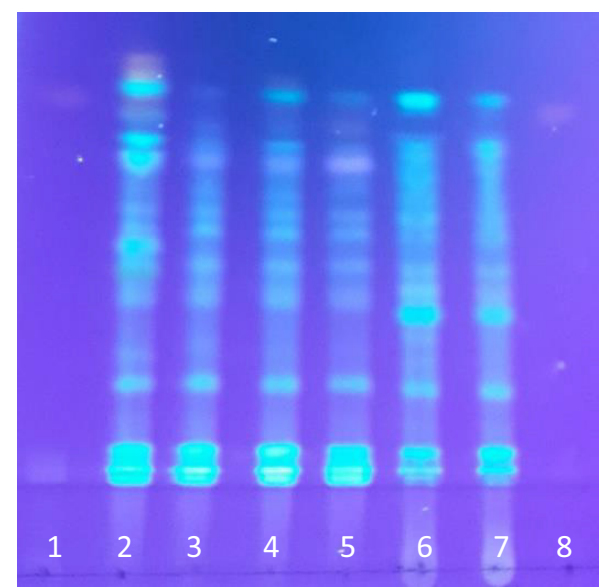

Fig. 1. TLC chromatogram of selected ST producing A. versicolor strains (1: ST standard; 2: SzMC 22332; 3 : SzMC 22333; 4: SzMC 22334; 5: flour-mill isolate Km26; 6: flour-mill isolate Km14 7: Aspergillus nidulans; 8: ST standard) 
3.2.2. ST detection in corn grit. The ST production of same set of strains described in 3.2.1. experiment was tested also on corn grit. ST production was below the detection limit in the case of strains A. versicolor SzMC 22335 and flour-mill isolates $\mathrm{Km} 11$ and $\mathrm{Km} 31$. A. nidulans control strain produced $10.4 \mu \mathrm{g} \mathrm{g}^{-1} \mathrm{ST}$, while strains A. versicolor SzMC 22333, SzMC 22332 and SzMC 22334 produced 186.2, 157.4 and $9.3 \mu_{g^{-1}} \mathrm{ST}$, respectively. For the flour-mill isolate Km14 this value was $12.3 \mu \mathrm{g} \mathrm{g}^{-1}$. The highest ST producer strain was the $\mathrm{Km} 26$ strain, newly isolated from the aerial sediment from the floor in Flour-mill A, with the extreme $277.1 \mu \mathrm{g} \mathrm{g}^{-1}$ toxin concentration (Fig. 2).

3.2.3. ST values detected in field studies. In field trials, one plot served as control and five plots were inoculated with the best ST producing isolate, Km26. Six days after midsilking, an Aspergillus strain infected toothpick was inserted in the middle of each upper ear and kept there until harvest (Fig. 3). There were two sampling times: 1. Seven weeks after inoculation and 2. Eleven weeks after inoculation (at full ripening). For toxin analysis, five average infected ears per plot were sampled. No ST could be detected at the first sampling time, but at the second

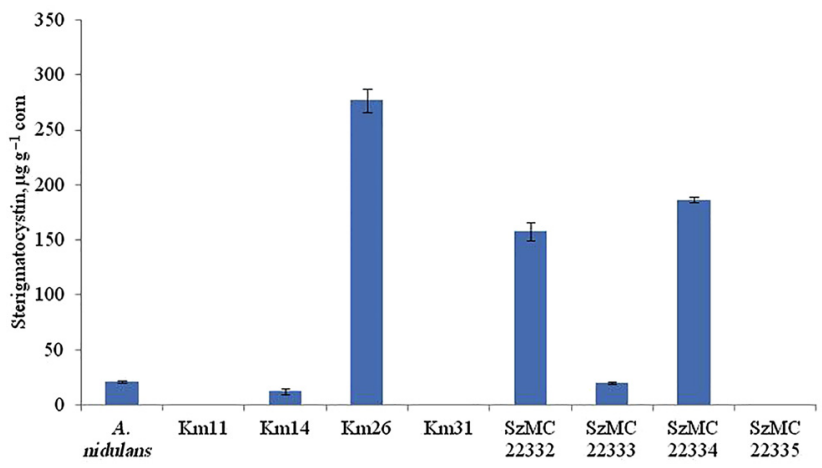

Fig. 2. Sterigmatocystin production of selected Aspergillus strains in corn grit measured by HPLC

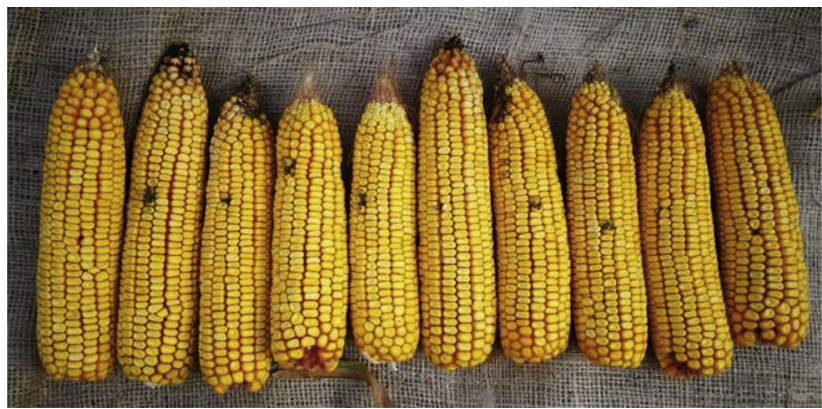

Fig. 3. Corn ears infected by A. creber $\mathrm{Km} 26$ by inserting a toothpick woven with mycelia 


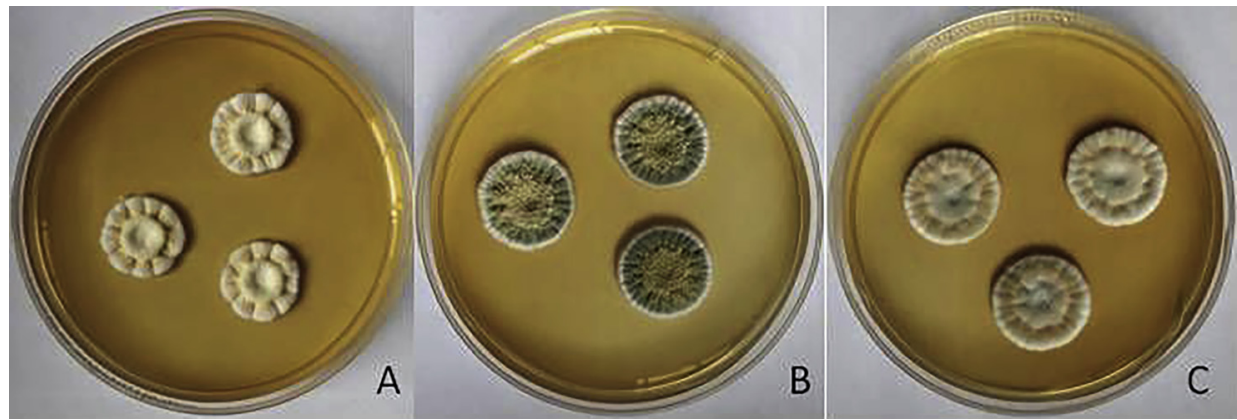

Fig. 4. Colony morphology of the three "best" ST-producing strains on Malt Extract Agar (Merck). A: A. creber Km26; B: A. griseoaurantiacus SzMC 22334; C: A. pepii SzMC 22332

sampling time Km26 infected plots exhibited relatively high toxin levels, up to $19.56 \mu \mathrm{g} \mathrm{kg}^{-1} \mathrm{ST}$ concentration could be measured.

\subsection{Taxonomic characteristics of selected ST-producing strains}

According to the results of our taxonomic identification (Westerdijk Fungal Biodiversity Institute, Utrecht, the Netherlands), the SzMC 22332 strain belongs to the species A. pepii D. Jakšić Despot, Kocsubé, Varga and Klarić; SzMC 22334 identified as species A. griseoaurantiacus Visagie, Hirooka and Samson; and Km26 belongs to the species A. creber Jurjević, S.W. Peterson and B.W. Horn (Jurevic et al., 2012) (Figs 4 and 5).

\section{CONCLUSIONS}

In the course of our work, Aspergillus strains were isolated from Hungarian mills. Strain Km26 showed strong ST production and it was identified as A. creber by sequence analysis of ITS, calmodulin and tubulin genes. The first A. creber strain was described in 2012 (Jurjevic et al., 2012), and it is known as major ST-producing species within the clad A. versicolor. Similarly to this strain, A. creber $\mathrm{Km} 26$ exhibited extreme ST production in corn grit with a value of $277.1 \mu \mathrm{g} \mathrm{g}^{-1}$. The ST production of this strain was also remarkable in field experiments, when corn was infected with it. In one out of three parallel plots a $19.56 \mu \mathrm{g} \mathrm{kg}^{-1} \mathrm{ST}$ concentration could be detected.

Here we report that ST-producing A. creber fungi appeared in Hungary, and the Km26 strain is the first known extreme ST-producer mould in the country. We were the first to report AFB1producing A. flavus strains that appeared in Hungary as a result of climate change (Dobolyi et al., 2013), but due to the sporadic appearance and different specific growth conditions of A. creber $\mathrm{Km} 26$, its appearance is probably not related to this effect. Based on our experiments, A. creber is rather a storage mould, but it also has weak plant pathogenicity. The de-novo genome project of $A$. creber $\mathrm{Km} 26$ is underway, and this will have a new impact on ST research. As future projects, we are planning to explore the effect of ST/Km26 contaminated feed on animals as we have already started this work on broiler chickens (Balogh et al., 2019). 


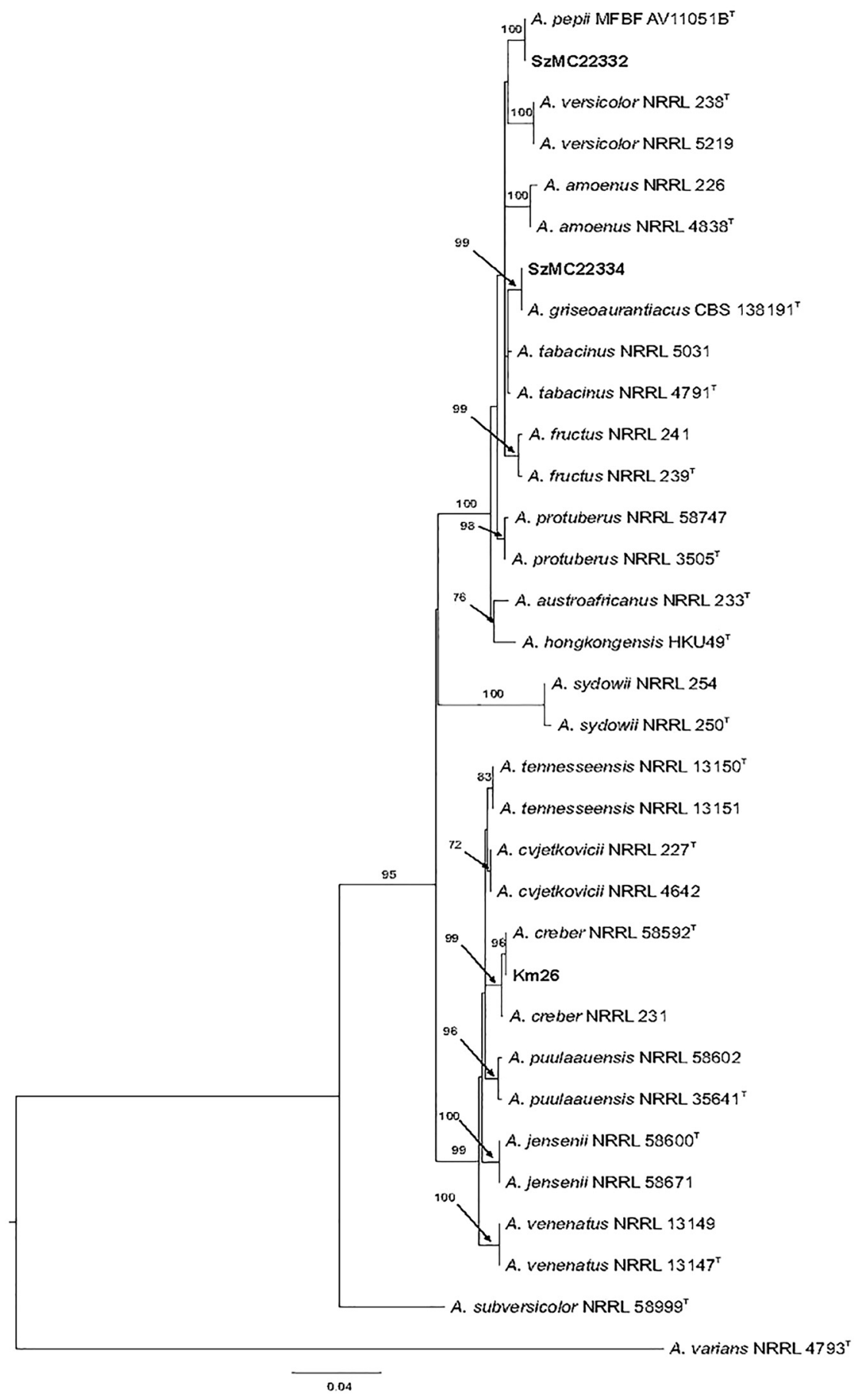

Fig. 5. Molecular taxonomic identification of the "best" ST-producing Aspergillus strains based on ITS, calmodulin, and tubulin sequence analysis. Km26 was identified as A.creber, SzMC22332 as A. pepii, and SzMC22334 as A. griseoaurantiacus 


\section{ACKNOWLEDGEMENTS}

The present study was supported by the Hungarian National Research Fund (OTKA 116631). The authors are also grateful for the strains provided by J. Varga and L. Karaffa.

\section{REFERENCES}

Aringoli, E.E., Cambiagno, D.E., Chiericatti, C.A., Basilico, J.C., and Basilico, M.L.Z. (2012). Mycoflora study in a wheat flour mill of Argentina. Brazilian Journal of Microbiology, 43(4): 1444-1451.

Balogh, K., Kövesi, B., Zándoki, E., Kulcsár, S., Ancsin, Z., Erdélyi, M., Dobolyi, Cs., Bata-Vidács, I., Inotai, K., Szekeres, A., Mézes, M., and Kukolya, J. (2019). Effect of sterigmatocystin or aflatoxin contaminated feed on lipid peroxidation and glutathione redox system and expression of glutathione redox system regulatory genes in broiler chicken. Antioxidants, 8: 201.

Bennett, J.W. and Klich, M. (2003). Mycotoxins. Clinical Microbiology Reviews, 16(3): 497-516.

Berry, C.L. (1988). The pathology of mycotoxins. The Journal of Pathology, 154: 301-311.

Chen, A.J., Frisvad, J.C., Sun, B.D., Varga, J., Kocsubé, S., Dijksterhuis, J., Kim, D.H., Hong, S-B., Houbraken, J., and Samson, R.A. (2016). Aspergillus section Nidulantes (formerly Emericella): polyphasic taxonomy, chemistry and biology. Studies in Mycology, 84: 1-118.

Demirci, M., Arici, A., and Gumus, T. (2003). Presence of patulin in fruit and fruit juices produced in Turkey. Ernahrungs Umschau, 50: 262-263.

Dobolyi, Cs., Sebők, F., Varga, J., Kocsubé, S., Szigeti, G., Baranyi, N., Szécsi, Á., Tóth, B., Varga, M., Kriszt, B., Szoboszlay, S., Krifaton, C., and Kukolya, J. (2013). Occurence of Aflatoxin producing Aspergillus flavus isolates in maize kernel in Hungary. Acta Alimentaria, 42: 451-459.

Gams, W., Christensen, M., Onions, A.H.S., Pitt, J.I., and Samson, R.A. (1985). Infrageneric taxa of Aspergillus. In: Samson, R.A. and Pitt, J.I. (Eds.), Advances in Penicillium and Aspergillus systematics, Plenum Press, New York, pp. 55-64.

Hubka, V., Nováková, A., Peterson, S.W., Frisvad, J.C., Sklenáŕ, F., Matsuzawa, T., Kubátová, A., and Kolařík, M. (2016). A reappraisal of Aspergillus section Nidulantes with descriptions of two new sterigmatocystin-producing species. Plant Systematics and Evolution, 302: 1267-1299.

International Agency for Research on Cancer (IARC) (1987). Overall evaluations of carcinogenicity. IARC Monographs on the Evaluation of Carcinogenic Risks to Humans, 7: 72.

Jakšić Despot, D., Kocsubé, S., Bencsik, O., Kecskeméti, A., Szekeres, A., Vágvölgyi, C., Varga, J., and Šegvić Klarić, M. (2017). New sterigmatocystin-producing species of Aspergillus section Versicolores from indoor air in Croatia. Mycological Progress, 16(1): 63-72.

Jurjevic, Z., Peterson, S.W., and Horn, B.W. (2012). Aspergillus section Versicolores: nine new species and multilocus DNA sequence based phylogeny. IMA Fungus, 3: 59-79.

Kozakiewicz, Z. (1989). Aspergillus species on stored products. Mycological Papers, 161: 1-188.

Leon, I., Stratton, J., Clough, J., Sehnalova, M., and MacDonald, S. (2015). Sterigmatocystin in cereal products. Final report. FS 102055. Fera Science Ltd., York (UK), p. 38.

Mol, H.G.J., Mac Donald, S.J., Anagnostopoulos, C., Spanjer, M., Bertuzzi, T., and Pietri, A. (2016). European survey on sterigmatocystin in cereals, cereals-based products, beer and nuts. World Mycotoxin Journal, 9(4): 633-642. 
Neme, K. and Mohammed, A. (2017). Mycotoxin occurrence in grains and the role of postharvest management as a mitigation strategies. A review. Food Control, 78: 412-425.

Németh, Z., Molnár, Á.P., Fejes, B., Novák, L., Karaffa, L., Keller, N.P., and Fekete, E. (2016). Growth-phase sterigmatocystin formation on lactose is mediated via low specific growth rates in Aspergillus nidulans. Toxins, 8(12): 354-368.

Peterson, S.W. (2008). Phylogenetic analysis of Aspergillus species using DNA sequences from four loci. Mycologia, 100: 205-226.

Scott, P.M. (1994). Penicillium and Aspergillus toxins. In: Miller, J.D. and Trenholm H.L. (Eds.), Mycotoxins in grain: compounds other than aflatoxin. Part Two. Eagan Press, St. Paul. 1994. S145.00 (viii +552 pages) ISBN 0962440752.

Szabó, B., Tóth, B., Toldiné Tóth, É., Varga, M., Kovacs, N., Varga, J., Kocsubé, S., Palágyi, A., Bagi, F., Budakov, D., Stojšin, V., Lazić, S., Bodroža-Solarov, M., Čolović, R., Bekavac, G., Purar, B., Jocković, D., and Mesterházy, Á. (2018). A new concept to secure food safety standards against Fusarium species and Aspergillus flavus and their toxins in maize. Toxins, 10(9): 372.

Tabata, S. (2011). Yeasts and molds - mycotoxins: aflatoxins and related compounds. In: Reference module in food science - encyclopedia of dairy sciences, 2nd ed., Elsevier, Tokyo, Japan, pp. 801-811.

Tsang, C-C., Hui, T.W.S., Lee, K-C., Chen, J.H.K., Ngan, A.H.Y., Tam, E.W.T., Chan, J.F.W., Wu, A.L., Cheung, M., Tse, B.P.H., Wu, A.K.L., Lai, C.K.C., Tsang, D.N.C., Que, T-L., Lam, C-W., Yuen, K-Y., Lau, S.K.P., and Woo, P.C.Y. (2016). Genetic diversity of Aspergillus species isolated from onychomycosis and Aspergillus hongkongensis sp. nov., with implications to antifungal susceptibility testing. Diagnostic Microbiology and Infectious Disease, 84: 125-134.

USDA (2006). Grain fungal diseases and mycotoxin reference. United States Department of Agriculture, Grain Inspection, Packers and Stockyards Administration, Federal Grain Inspection Service. STOP, 3630: 20250-3630.

Weidenbörner, M., Wieczorek, C., Appel, S., and Kunz, B. (2000). Whole wheat and white wheat flour-the mycobiota and potential mycotoxins. Food Microbiology, 17(1): 103-107.

WHO (2018). Mycotoxins. https://www.who.int/news-room/fact-sheets/detail/mycotoxins.

Zhao, Y., Wang, Q., Huang, J., Ma, L., Chen, Z., and Wang, F. (2018): Aflatoxin B1 and sterigmatocystin in wheat and wheat products from supermarkets in China. Food Additives \& Contaminants Part B Surveillance, 11(1): 9-14.

\section{SUPPLEMENTARY MATERIAL}

The online version of this article offers supplementary material https://doi.org/10.1556/066. 2020.00326 .

Open Access. This is an open-access article distributed under the terms of the Creative Commons Attribution 4.0 International License (https://creativecommons.org/licenses/by/4.0/), which permits unrestricted use, distribution, and reproduction in any medium, provided the original author and source are credited, a link to the CC License is provided, and changes - if any - are indicated. (SID_1) 